\title{
Colliding intervention in the spatial management of street-based injecting and drug- related litter within settings of public convenience (UK)
}

'Shopper finds needles in Taunton public toilets’
Somerset County Gazette (27 December 2012)

'Drug users arrested in Cambridge's 'health hazard' loos' Cambridge News (03 April 2013) ${ }^{2}$

'Ely's public toilets 'rife' with drug activity' Ely Weekly News (19 April 2013) ${ }^{3}$

'Council cleaner's HIV-test wait after drug needle stab in Sunderland toilets' Sunderland Echo (30 July 2013) ${ }^{4}$

'Call for 'drug haven' conveniences to be closed' Hastings and St Leonard's Observer (14 December 2013) ${ }^{5}$

Presented above are examples of local news headlines that have been reproduced from online versions of various provincial English newspapers. These articles report upon events located throughout the length and breadth of England during a 12-month period from 2012 to 2013. These selected items however do not adequately represent the full extent of similar reportage that occurs throughout the UK on a weekly basis. Nonetheless, the above headlines do provide an indication of the key issues underlying this paper. Namely, the relationship between street-based injecting drug use; the UK's policy of harm reduction, the appropriation of public toilets as settings for episodes of injecting drug use and the statutory (mis)management of drug-related litter. As will be demonstrated throughout this paper, the relationship between these features of UK urban environments is one defined by colliding and clashing policy perspectives at a structural level.

In essence, the colliding relationship that exists between the aforementioned topics perhaps reflects flawed strategies within national drug policy frameworks (of the UK). More specifically, although street-based injecting undoubtedly occurs throughout urban and rural locations of the UK (as indicated by the above headlines) there is currently no formal national policy (and/or good practice guidelines) that provides direction, guidance or advice on how such matters may be best managed by the relevant authorities/services at a local/frontline level. Instead, local authorities are expected to implement and deliver a regionalised version of a generic, national policy known as the government's Drug Strategy. In the absence of a specific policy relating to street-based injecting, local authorities therefore have to adapt and respond in accordance with the current strategy in addition to applying the enforcement

\footnotetext{
${ }^{1}$ http://www.somersetcountygazette.co.uk/news/10129034.Shopper_finds_needles_in_Taunton_public toilets/?r ef=rss

${ }^{2}$ http://www.cambridge-news.co.uk/Cambridge/Drug-users-arrested-in-Cambridges-health-hazard-loos20130405151852.htm\#ixzz2nqMgEoRz

${ }^{3}$ http://www.ely-news.co.uk/News/Elys-public-toilets-rife-with-drug-activity20130419095033.htm\#ixzz2nqV9xVmY

${ }^{4}$ http://www.sunderlandecho.com/news/crime/council-cleaner-s-hiv-test-wait-after-drug-needle-stab-insunderland-toilets-1-5901925

${ }^{5}$ http://www.hastingsobserver.co.uk/news/local/call-for-drug-haven-conveniences-to-be-closed-1-5745846 
procedures attached to policing 'criminal' behaviour associated with possession of illicit substances. Accordingly, local responses to street-based injecting may typically involve spontaneous, reactive, interventions that lack strategic vision and/or planning in which harm reduction approaches may receive only limited attention. Such ad hoc procedures typically involve the coercive management of public places by physical manipulation (involving the closure, removal or limiting of access to affected areas) or the environmental re-design of communal spaces (using blue lights, barriers, CCTV, removal of flora/screens etc.) ${ }^{6}$. One plausible explanation for this reactive response to street-based injecting possibly relates to the thematic design of successive Drug Strategies since their initial inception over three decades ago.

Single Issue Drug Strategies in the UK: Harm Reduction, Treatment, Abstinence and Recovery

Since the 1980s, various elected UK governments have typically prioritised a single-issue theme that characterises the relevant Drug Strategy of successive public health policy frameworks (Berridge 2012). Similarly, each single-issue theme has typically rested upon the 'four pillars' (of enforcement, education, prevention and treatment) that characterise international drug policy (Heed 2006, MacPherson et al 2006, Room 2006). In the UK, initial responses to the HIV/AIDS epidemic during the mid-1980s adopted a significant harm reduction approach to drug policy in an attempt to curtail the epidemic (Stimson 2000). In fact, it was during this particular period that 'needle exchanges' were formally introduced to the British high street as part of attempts to reduce the spread of HIV (Stimson et al 1998). Successive strategies from 1995 to 2008 (Department of Health 1995, Cabinet Office 1998, HM Government 2008) however have typically adopted a more punitive and coercive ethos, in which drugs and related harms were situated within a specific drugs-crime nexus (Stimson 2000, Strang and Gossop 2005, Monaghan 2012). In this regard, the overriding policy issue became one of treatment for drug use, in which a society metaphorically 'sick' with crime and drug use may be best treated by clinical intervention. Similarly, the introduction of a more abstinence-orientated Drug Strategy (HM Government 2008, Scottish Government 2008) was a strategy that mainly prioritised drug-free lifestyles. Indeed, the latter was almost certainly the forerunner of the present day Strategy that is dominated by the single issue of recovery from dependence (Galvini 2012, Monaghan 2012). Throughout each of these phases, harm reduction has consistently been included as a complementary and necessary intervention that typically supports the overriding theme of the relevant Strategy. However, in the most current period (2010- ) recovery (from drug dependence) is often (explicitly and implicitly) associated with 'economic productivity' and a more 'aspirational nation' (Cameron 2012). Indeed, the diminished and diminishing role of harm reduction within the current Strategy is made explicit by the Home Secretary. More precisely, Theresa May MP states:

A fundamental difference between this strategy and those that have gone before is that instead of focusing primarily on reducing the harms caused by drug misuse, our approach will be to go much further and offer every support for people to choose recovery as an achievable way out of dependency. ... The solutions need

\footnotetext{
${ }^{6}$ The wider ethnographic research attached to this work has noted that attempts to manage street-based injecting in this manner do not necessarily remove the activity from the built environment. Instead such coercive practice typically tends to displace and disperse people who use drugs to more marginalised, more concealed settings of harm production (Parkin 2008, 2011a, 2013).
} 
to be holistic and centred around each individual, with the expectation that full recovery is possible and desirable. (HM Government, 2010, 2 emphases added)

As harm reduction may not have the prominence in UK policy as in previous years, it is perhaps necessary to contextualise the centrality of this global paradigm in public health initiatives.

Harm reduction as public health policy framework

Following an epidemic of HIV identified in an area of Edinburgh (Robertson 1990), the government's Advisory Council on the Misuse of Drugs (ACMD 1988) advocated that management of the virus be given greater priority than the prevention of injecting drug use per se. Towards such public health goals, decisions were taken to introduce basic harm reduction initiatives ${ }^{7}$ that have since become embedded within various national Drug Strategies by the successive governments of England, Northern Ireland, Scotland and Wales (Monaghan 2012).

Since their formal introduction in 1987 (Stimson et al 1988), British-based needle and syringe programmes (NSP) continue to operate from drug services, primary care settings, community pharmacies or as part of outreach initiatives directed at specific populations (such as sex workers, homeless/roofless). As noted by the National Institute for Health and Care Excellence $^{8}$ (NICE 2014), the original purpose of NSP initiatives continue to be the foundation of current service provision. For example, the primary aim of providing free, sterile injecting equipment (including paraphernalia such as swabs, filters and cookers) is to reduce the transmission of blood borne infection caused by the shared use of injecting equipment. However, NSPs also continue to provide advice and information on safer injecting technique, avoiding overdose; access to facilities for disposing used equipment and provide a street-based gateway to services such as blood-testing, vaccination and treatment options (such as opioid substitution therapy [OST]).

Statutory support for NSPs is further acknowledged in the 2010 Drug Strategy (HM Government 2010). More specifically, within a strategy that prioritises recovery from drug dependence and the goal of drug-free lifestyles, NSPs are acknowledged as initiatives that may facilitate this goal in reducing drug-related harm and the spread of blood-borne viruses (NICE 2014). Indeed, this recognition and support of NSPs as an essential public health initiative is perhaps confirmed by the ongoing shared use of needles and syringes in addition to the sharing of filters, cookers and water by people who inject drugs (NICE 2014, Public Health England (PHE) 2013b). Furthermore, national (UK) estimates of blood borne virus amongst people who inject drugs report of almost $50 \%$ prevalence for hepatitis $\mathrm{C}$ (approximately 215,000 individuals) and approximately 1\% for HIV (Health Protection Agency (HPA) 2012, PHE 2013a, b). As such, there is a recognised need to sustain the development of NSPs as a legitimate form of public health intervention and as a valid response to the street-based injecting drug use that occurs (often unreported) in towns and cities throughout the UK on a daily basis.

\section{Street-based Injecting: an overview}

\footnotetext{
${ }^{7}$ Needle and syringe programmes and opioid substitution therapy

${ }^{8}$ According to the NICE website, this is a Non Departmental Public Body (NDPB) independent of government, but sponsored by the Department of Health. It is an organisation that provides advice and guidance to improve health and social care (see www.nice.org.uk).
} 
Street-based (or 'public') injecting typically involves the preparation and injection of controlled substances (such as amphetamine sulphate, cocaine, crack-cocaine and heroin) within environments that are generally accessible to (and/or frequented by) members of the general public. Street-based injecting environments may be located within community spaces and temporarily appropriated by people who use drugs for the purposes of preparing and injecting drugs. Such locations may be further categorised as either 'public' or 'semi-public'; with toilets, parkland and alleyways exemplifying the former - and parking lots, abandoned buildings, wasteland and stairwells comprising the latter.

Academic studies of street-based injecting has intensified and expanded at a rapid pace since 2001. Most notably, a substantial body of work from Australia, Canada and the UK has considered the impact of 'place' upon injecting practice and related harm (DeBeck et al., 2009; Dovey et al., 2001; Fitzgerald et al., 2004; Fitzgerald, 2005; Fry, 2002; Green et al., 2003; Hunt et al., 2007; Marshall et al., 2010; McKnight et al., 2007; Navarro and Leonard, 2004; Parkin 2009, 2011b, 2013, 2014, Parkin and Coomber 2009a,b, 2010, 2011a,b, Pearson et al 2011, Rhodes et al., 2006; Rhodes et al., 2007; Small et al., 2007; Taylor et al., 2006). This collective international interest in street-based injecting drug use has provided a range of shared qualitative findings regarding the appropriation of public space and injecting-related hazard that typically prioritise the perspectives of people who inject drugs. For example, it is now widely accepted that street-based injecting emerges from various 'situational necessities' (Rhodes et al. 2007, 276). That is, the inter-relationship of influences such as homelessness, socio-economic disadvantage, drug dependence, drug-cravings and various spontaneous 'opportunities' (unexpected access to drugs and/or injecting space).

In addition, the above studies have noted that street-based injecting episodes are characterised by 'urgency' and a desire for 'privacy' whilst accessing public locations. Urgency is a requirement that avoids detection and interruption (by authority figures such as police, security guards in addition to members of the public). An urgency to inject quickly often influences inappropriately prepared drug solutes and a hurried administration of the actual injection (Parkin 2011b, 2013, 2014, Dovey et al. 2007, Small et al. 2007). Privacy is regarded as essential for concealing an intimate act whilst in possession of an illicit substance (ibid). For each of the above reasons, free-to-access public toilets that provide cubicles (with doors that can be locked from within) have been noted as popular and preferred environments by people regularly involved in street-based injecting drug use (ibid).

\section{Tackling Drug-related Litter: A British Response to Street-based Injecting}

As a consequence of increased reports of needlestick injuries within community settings, in addition to increasing levels of discarded injecting equipment 'in the general environment', Philipp (1993) comments that these concerns mark the emergence of a 'new public health problem'. The newspaper headlines at the onset of this paper demonstrate that this continues to be a contemporary and controversial issue within British communities over two decades later.

Despite concerns surrounding discarded injecting equipment, it was not until October 2005, that the UK government's Department for Environment, Food, and Rural Affairs (Defra) published a report titled Tackling Drug-related Litter. This document is dedicated to the issue of managing drug-related paraphernalia that may be found in street-based settings. In essence, Tackling Drug-related Litter was produced in recognition that discarded injecting equipment in public settings may 'create a very real fear of infection and disease, (and) acts as a stark reminder of the wider harm caused by the misuse of drugs' (Defra, 2005, ii). 
Tackling Drug-related Litter also provides a series of recommendations for managing and reducing the 'growing problem' (Defra 2005, 1) of discarded paraphernalia in various locations; the concomitant 'fear, anger, disgust and frustration' (ibid.) such items may generate, in addition to the perceived and actual harms attached to discarded injecting equipment in community/public settings. Similarly, throughout the report, Defra continuously advocates the formation of local partnerships and joint-working initiatives as a means of implementing a locally coordinated and effective response to the management of discarded drug-related paraphernalia (and by inference, street-based injecting). As such, Defra's (2005) statutory vision of a joined-up approach to public health and community safety prioritises ongoing liaison and intervention between local authorities, community organisations, police constabularies, drug/alcohol services and all frontline employees that may have contact with discarded equipment (whether in the public or private business sectors).

Of further import is that whilst Tackling Drug-related Litter and its various recommendations seek to promote community safety and public health, there is also underlying support for the practice and principles of harm reduction throughout the report. For example, the benefits of harm reduction intervention as part of the UK Drug Strategy is made explicit, particularly with regard to needle and syringe distribution and the relationship between drug use and sex work (Defra, 2005, pp.3-4). Similarly, many of Defra's recommendations for 'tackling' drugrelated litter in community settings are premised upon pre-existing examples of 'good practice' noted throughout the UK, in which public health, community safety and harm reduction are often central tenets of the interventions cited.

A total of 14 recommendations regarding the management of drug-related litter are made by Defra. Of these, almost all emphasise the importance of co-ordinated responses to the surveillance, management, collection and disposal of drug-related litter. Similarly, at least 11 of these 14 recommendations endorse some form of harm reduction intervention. For example, Defra suggests that local authorities and community organisations may be more proactive in formalising agreements regarding positive policing of used needle possession, the siting of sharps bins in public toilets, avoiding the installation of blue lights ${ }^{9}$ in public settings and providing training for all people who may encounter discarded equipment during the course of their employment. Indeed, the specific intervention described later in this paper (safer toilet design via the 'Cambridge Model') is one that has been promoted and supported by central government policy-makers as an example of best practice - as it is one that proactively seeks to minimise drug-related hazard within community settings (Defra 2005; 37). Each of the aforementioned activities may be described as those that seek to alter the physical environment in which they are located for the benefit of affected communities. Indeed, such projects may be further regarded as exemplars of 'enabling environments' (Duff 2009, Moore and Dietze 2005) that purposely seek to remove obstacles at a situational / structural level in order to facilitate the practice of harm reduction (Rhodes 2002, 91).

At this point, it should also be noted that Defra is not a body responsible for any government policy regarding illicit drug use. Nevertheless, it is a statutory body that works in conjunction with other central government departments (namely the Home Office and Department for Health) in promoting the current Drug Strategy (Defra 2005, i). As such, Tackling Drug-

\footnotetext{
${ }^{9}$ Researchers in England and Canada (Parkin 2009, 2013, 2014, Parkin and Coomber 2010, Crabtree et al 2013) have each concluded that the installation of fluorescent blue lights designed to prevent injecting drug use can contribute to participation in more harmful injecting practice by those involved in more regular street-based injecting episodes.
} 
related Litter may be regarded, at best, as an advisory document that provides a recommended template for good practice guidance, to be considered by all local authorities throughout the UK. Accordingly, Defra's (2005) recommendations provide options for local authorities and should not necessarily be interpreted as a template for national implementation.

\section{The 'Cambridge Model' of Safer Public Toilet Design}

An explicit illustration of good practice in the management of drug-related litter relates to an initiative identified by Defra (2005) in the city of Cambridge (UK) and implemented by the local authority of that location. In this example, the provision of public conveniences, (similar to that contained within Image $1^{10}$ ), is applauded and commended as an environment that appropriately 'tackles' drug-related litter in community settings. More accurately, the relevant toilet design aims to minimise incidents of needlestick injury (via spatial planning and spatial management) and simultaneously provides opportunities for the discrete disposal of assorted sharp items in public places whilst concealed from public view. It is especially due to the latter reasons that the overall design is regarded as a model of good practice in the environmental management of public health and community safety ${ }^{11}$.

Elsewhere, the author (Parkin 2014) presents a series of photographic images that visualise and demonstrate the 'Cambridge Model'12 as 'gold standard' design in the management of drug-related litter within public conveniences as suggested by Defra (2005). However, in the absence of such images here, the design in summary consists of several stand-alone, unisex, toilet cubicles grouped together as a single unit in a prominent 'high street' location. In addition, the overtly public location and noticeable 'chalet' design of the unit aims to maximise naturally-occurring surveillance of any 'suspect' behaviour associated within or around the immediate vicinity of the unit. These design features are applauded by Defra, as they facilitate the provision of public amenity where formalised supervision (by local authority employees or other frontline service personnel) may not necessarily be available.

The commendable design of the chalet-unit continues within each individual cubicle, in which discrete signage notifies patrons of the location of 'sharps bins' adjacent and above washbasins. Furthermore, these notices feature visual icons of objects deemed suitable for disposal within the 'birdhouse' opening located upon the internal fascia unit (see Image 1). As such, appropriate items for disposal include needles and syringes in addition to other objects associated with washroom attendance (such as razor blades and safety pins). In some settings, Braille-notification also accompanies these icons in order to inform those experiencing visually-impaired difficulties of the relevant disposal facilities. Overall, the symbolic, textual, tactile and visual ambiguity of the signage is a further demonstration of creditable design. This is because the non-specific notice advises the public of facilities designed for the discarding of sharp items per se rather than identify specific objects relating explicitly to injecting drug use. Accordingly, this more neutral and impartial notification possibly minimises concerns relating to any community unease associated with the

\footnotetext{
${ }^{10}$ Image 1 and Image 2 are not of the public toilets in Cambridge described in the Defra (2005) report. Instead, they are photographs taken during the author's fieldwork of public toilets that may be regarded as 'almost identical' to the 'Cambridge model' advocated by Defra (i.e. same toilet, different location)

${ }^{11}$ Such facilities are not purposely designed to house injecting episodes

12 The actual design is that of a Swedish public toilet manufacturer who produce bespoke, stand-alone conveniences in a variety of European countries (see www.danfo.com ), whereas the 'Cambridge Model' is a term coined by the author for purposes of convenience (sic) only.
} 
immediate community, environmental, social and physical setting (pertaining specifically to drug issues and illustrated in the newspaper headlines above).

$<$ Image 1 here $>$

Other commendable features within the unit that contribute to 'safer toilet design' include self-contained hand-washing facilities (providing access to hot, running water, soap and drying facilities); comparatively more comfortable and more hygienic space in private settings and the provision of alarms in the event of emergency. Moreover, the absence of flat surfaces, ledges and shelves further minimise the amount of littering spaces available for the discarding of injecting paraphernalia. As such, the overall design within these toilet units is viewed positively by Defra (2005), as the spatial minimalism within aims to purposely reduce opportunities for needlestick injury to occur amongst all patrons who attend public toilets (including those who may work there).

Although bespoke public conveniences such as that described above have been designed specifically with community safety in mind, they also (perhaps inadvertently) provide amenity for housing opportunities for harm reduction practice (due to safe, private, concealed space containing adequate lighting as well as cleansing and disposal facilities). At this point, it is perhaps crucial to emphasise that it would be irresponsible for any professional body to advocate toilet environments as 'recommended' sites of safer injecting drug use. However, in the context of street-based injecting, (in which lifestyles are often characterised by transience, homelessness, rooflessness, unemployment and poverty), public conveniences per se do provide temporary injecting-niches that facilitate attempts at reducing drug-related harm (Parkin 2013). Similarly, as noted earlier, episodes of street-based injecting regularly take place within public toilets on an international scale and are spatially-related to 'situated necessities' of those typically participant in street-based injecting.

As such, the use of toilet facilities as settings for episodes injecting drug use is a topic that is bookended by particular policy frameworks. That is, on one side, NSP settings provide the means and equipment to conduct 'safer' injecting (but not the 'space' to do so); and on the other a series of guidelines and recommendations dedicated to the clearance of the same items when discarded in public settings (i.e. spatial management of people and place). Streetbased injecting episodes within public conveniences therefore bridge these particular concerns. However what actually happens at 'ground zero' with regard to the policies of harm reduction and the management of street-based injecting is not necessarily consistent with these particular policy designs. This latter issue is addressed in the following section that summarises relevant findings from empirical ethnographic research located in the south of England during 2006-2011.

\section{The Research}

The account described below emerged from a series of ethnographic studies of street-based injecting that were each located in various urban centres $(x 4)$ throughout the south of England (Parkin 2009, 2011, 2013, 2014, Parkin and Coomber 2007, 2008, 2009a,b,c 2010 2011a,b, Pearson et al 2011) ${ }^{13}$. All studies attached to this project were examples of applied action

\footnotetext{
13 The initial study (2006-09) was conducted as the author's doctoral research and was funded by a CASE Studentship provided by the Economic and Social Research Council of Great Britain as well as by a relevant body within local government of the setting concerned (a body formerly known as a Drug and Alcohol Action Team that was responsible for the implementation of the national Drug Strategy at a local level). Research conducted during the period 2010-11 may be regarded as 'post-doctoral' and furthered studies of the same topic.
} 
research that were commissioned (in full or in part) by assorted local authorities as part of rapid appraisal responses to street-based injecting drug use. All research and associated methods were ethically approved by the relevant committees.

Throughout the 5-year period of research a total of 71 people with experience of injecting drugs within a street-based setting ('in the last month') were interviewed (predominantly within NSP settings). Throughout the collapsed cohort, a typical male respondent $(n=54)$ was aged 36, white British and originated from the immediate local area. This person would be currently unemployed; have experience of rooflessness, report current homeless and have spent time in prison as a result of drug-related offences. Similarly, a typical female respondent $(n=17)$ was aged 30 , white-British and also from the immediate local setting. This person would also have experience of rooflessness, report current homeless, be unemployed and have some experience of sex work. The average injecting career across the cohort was 11 years (although 13.5 years for male respondents and 6 years for female respondents). The overall profile of this particular cohort was therefore characterised by midadulthood, long-term drug dependence with widespread experience of socio-economic exclusion and unstable housing.

Furthermore, 169 frontline service personnel (e.g. toilet attendants, car park attendants, police officers, drug workers, outreach teams, security guards etc) were also interviewed regarding their experiences of managing street-based injecting. In addition, over 400 street-based injecting environments were attended by the author, accompanied by people who inject drugs and/or by frontline service personnel. Also attached to the various studies was a significant visual research component in which the author attempted to 'picture harm reduction' with the use of photography and video (collecting over 1000 images of injecting environments and over one hour of video material).

Due to the qualitative design of this ethnographic project, methods of data generation included various forms of interviewing (unstructured, structured and semi-structured), participant observation, direct observation and observant-participation, as well as the use of the aforementioned visual methods. More detailed accounts of the above (including the epistemology, ontology and rationale underlying each study) are documented in the relevant texts (Parkin 2013, 2014).

Presented below are findings relevant to the above discussion that relate specifically to harm reduction, public conveniences (the 'Cambridge Model' in particular) and the management (by various authorities) of street-based settings appropriated for injecting episodes as noted in one particular setting ${ }^{14}$.

The views of people who inject drugs within the 'Cambridge Model' of safer toilet design The following section summarises the views, opinions and experiences of people who inject drugs that relate exclusively to the 'Cambridge Model' of safer toilet design as portrayed in Images 1 and 2. These views were obtained from one of four settings during the multi-site ethnography described above. In addition, the urban centre concerned was the only location in the study where the 'Cambridge Model' was made available by statutory authority. The respondent cohort (x20 individuals) relevant to the location in question was familiar with the various units that were located throughout the relevant urban centre (consisting of approximately 20 toilet cubicles within 3 stand alone units). In addition, most of those

${ }^{14}$ Purposely not identified for reasons relating to 'anonymity' of setting 
interviewed had direct experience of using the toilet cubicles as a location for conducting injecting episodes. Similarly, consensus amongst those interviewed was that the drug-related litter bins within the toilets were a positive attempt by local authorities to proactively address street-based injecting in the urban centre concerned. Of these respondents, several individuals recognised the public health and community safety agenda that typically underlies such initiatives. For example:

I've noticed in some places they are putting sharps boxes and I think, "well, that's not encouraging (street-based injecting)". I think it's realistic. They know (street-based injecting) is happening. And, it's better than people leaving (injecting paraphernalia) on the floor, because, like, Hep $\mathrm{C}$ virus can stay alive for 90 days (outside of the body) ...(Respondent 08, Male)

I think it's a great idea. I thought it was very well thought out because obviously there are people that are injecting and they don't want (to keep) needles on them ... and not everyone is of the state of mind just to put the lid back on. So you don't want people coming across (discarded sharps) and getting it in the foot or whatever. I think it's a great idea that there is a place where they can be disposed of safely ... (Respondent 20, Male)

However, the presence of public toilets equipped with facilities for depositing injecting paraphernalia was also viewed with some confusion relating to an 'operational ambiguity'. For example, some respondents were of the belief that the relevant local council were explicitly 'catering for' street-based drug users in providing informal, locally-sanctioned, environments of injecting drug use. In these particular responses, the term 'safety' was not used in the context of public health. Instead, 'safety' was used as an indigenous expression to describe the absence of police intervention, in settings (toilets with sharps bins) which appeared to offer a temporary sanctuary from possible arrest. For example:

I don't know if it's because they've (injecting drug users) been told it's a safer place, but what I've noticed in them toilets is you've got a hole for sharps and stuff like that. So I don't know if they've like ... they probably like seen that in the past and thought, "Yeah you can go there (to inject) ... it's a safe place to come and go" because of that. (Respondent 18, Male, emphasis added)

Similarly:

Well it's safe I suppose because if you didn't have a 'cin bin (portable sharps container) on you, you can at least discard your needle safely (in there). (And) because you can lock the (toilet door) and if people are sort of like 'pee-ing' in there when they (inject), they'd be able to discard everything anyway. So nobody would know that they had been (injecting) there anyway. (Respondent 16, Female, emphasis added)

Indeed, this spatial ambiguity is further supported in the following extract in which the respondent perceives the 'Cambridge Model' of toilet design as a semi-formal injecting setting that is simultaneously the focus of increased police surveillance of people who inject drugs (and their arrest). 
I've been arrested in a few toilets as well, when I've been standing (injecting) in the toilets (cubicles). I've used them a lot of the time (for injecting heroin). And there's also toilets which are the same (design at a nearby location). And ... on the wall they've got the needle bin ... where you put needle disposals and all sorts like that. So really ... (street based injecting) is sort of, like, being catered for, isn't it? It is, isn't it? Really, it is. If you've got them amenities in there. (Respondent 03, Female)

Similarly:

In public toilets, the (sharps) facilities some of them have, I think, should be made more widespread ... but only on the basis that we can go to these places discretely, with discretion and without the fear of having that bang, bang, bang. "We're (police) outside waiting for you”. (Respondent 01, Male)

Nevertheless, the ambiguity and function of settings equipped with sharps bins is perhaps superfluous in the context of street-based injecting, especially when considered alongside associative issues such as drug dependence, homelessness, avoiding arrest and addressing withdrawal symptoms. Indeed, when situated within these particular experiences of injecting drug use, any environmental ambiguity associated with places of shelter is diminished in the pursuit of 'feeling well again'. For example:

... put it this way, if you're feeling that rough and you've got a bag (of heroin), you've got your works on you, you'll find a way of doing it and you will find a place to do it. And obviously if those toilets are there and they've got sharps facilities to be used then I think it's probably better for everyone concerned to (inject there) ... . but I don't think it's promoting you to do it there because (street-based injecting) is not everyone’s cup of tea. (Respondent 07, Male)

Similar sentiments to each of the aforementioned points may be noted in the following extract in which the individual recognises the value attached to the safer design features within the relevant public toilets. However, the added inference regarding an absence of more 'specialised' harm reduction provision for people who inject drugs ('us') and who may continue to inject within public conveniences adds poignancy to this particular observation.

I'm assuming it's the council that have obviously put this all into process. But when the toilets were going to be built, (they must have said) "Right, well let's put this into the equation to make it better". I don't think it's better for us ((laughs)) but it is better for the general public. (Respondent 12, Male, emphasis added)

Indeed, the limited harm reduction value afforded by toilet cubicles per se is further noted in the following comment. In this extract, the respondent articulates how the immediate and positive benefits afforded by 'place' may be forever reduced by the negative consequences of injecting drugs behind locked doors of public conveniences (whether they are equipped with sharps bins or not).

((sighs)) ... (the toilets are) a good thing as in that you've got somewhere to go. But it's a bad thing because if you lock yourself in, and you go over (overdose), then you're fucked ... (Respondent 17, Male) 


\section{Ethnographic Observations}

Whilst the above views typify those from a cohort of street-involved, mainly homeless people who report long term dependence to heroin and/or crack cocaine, it is evident that the 'Cambridge Model' of toilet provision is viewed positively and with suspicion by those who inject drugs. In short, the spatial ambiguity and operational rationale of providing public toilets equipped with drug-related litter bins appears to raise confusion regarding the 'official' intent and purpose of the receptacles.

As a means to further comprehend this confusion, suspicion and uncertainty one perhaps needs to fully appreciate the immediate environmental setting in which one of the units was situated at the time of fieldwork (2011). Image 2 (below) presents a visual depiction of ethnographic observation conducted at the site concerned during a three-month period of fieldwork (by the author; conducted alone and/or whilst accompanied by frontline service personnel). In the relevant environment, multiple injecting episodes were known to take place (by numerous services) on a regular basis. The image presents a rear view of the toilet block (located adjacent a parking lot in a 'high street' location) and is surrounded by textblocks that aim to 'map' a variety of (drug-related) services and interventions that surrounded this particular setting on a daily basis.

Accordingly, the immediate environment adjacent the toilet block was frequented by streetbased drug sellers as well as by people who inject drugs. Nearby was a hostel that provided short-term accommodation for those reporting homelessness and/or multiple dependence issues (in which staff were reported to enforce penalties and sanctions for ownership of injecting paraphernalia whilst on the premises). Opposite the toilet block was a community pharmacist that dispensed methadone prescriptions for those attending a drug treatment centre in the town centre; a mobile needle and syringe programme visited the parking lot at specific times of the week and (statutory and third sector) outreach workers regularly patrolled the area due to known associations with rough sleeping. In addition to the above, the immediate environment was under constant surveillance by CCTV cameras that were positioned immediately outside (and focused upon) the toilet block; 'hi-viz' policing regularly occurred around the area (with patrol cars/vans often stationed nearby) and 'plainclothes' ('undercover') police officers were known to operate throughout the vicinity. Finally, despite the constant presence of policing and/or surveillance, the installation of fluorescent blue lights within the toilets was also considered as a possible 'solution' to prevent future episodes of injecting drug use in the relevant toilet unit. (It later became evident to the author that the relevant body was also aware that such installations were the antithesis of Defra recommendations and contrary to the recommended design of public toilets per se).

\section{$<$ Image 2>}

Upon awareness of the various forms of environmental management employed by various bodies of local and statutory authority within this setting is made apparent, the confusion and suspicion held by people who inject drugs in this location is perhaps further clarified. Indeed, from the perspective of those who do not inject drugs, it is perhaps unclear what is to be achieved by the implementation and availability of multiple interventions in the vicinity that both enable and problematise harm reduction within such a concentrated and contained area. As such, it is feasible to suggest that this uncertainty relates to a conflict of interest associated with the four pillars of (UK) drug policy, in which 'prevention', 'treatment' and 
'enforcement' services collide within and around a particular environmental setting known for injecting drug use (the toilet cubicles). However, the overall effect of this 'colliding intervention' is the delegitimizing and disconnecting of attempts to influence harm reduction intervention/practice within that specific location. Whilst this generalisation may initially appear somewhat sensationalist, it may be further validated by events noted in Cambridge both during and after the collection of all data during the author's fieldwork. This is described in full detail in the following section.

\section{The Rise and Fall of the 'Cambridge Model'}

Although the author did not conduct any fieldwork in the city of Cambridge at any point during the study, communications were exchanged with a Manager of street services in connection with discussions regarding the implementation and operation of the toilets described in the Defra (2005) report. For example, with regard to the perceived impact the 'Cambridge Model' had upon drug-related litter and street-based injecting in Cambridge itself, the aforementioned Manager wrote the following to the author (circa 2009 emphases added):

We have 60 toilet cubicles with this type of disposal. I can say these disposal facilities are heavily used. We use 7 litre sharps containers and in some high use toilets we can change a bin once a week. We have never counted the number of syringes but know that the majority of syringes seem to be 1 or 2 mil (barrels) but there are also a significant number of 5 mil (barrels). What (the bins have) done is greatly reduce the number of needles found in the area around the toilets.

In one case, where the toilets are in a multi-storey car park, prior to the toilets being modernised, used needles were regularly found in the car park. Since the toilets now have needle disposal, it is rare for a used needle to be found in the car park. The approach taken (by the relevant local authority) in providing needle disposal in public toilets was quite controversial. However, our legal advice and risk assessment at the time put public - and staff- safety first and therefore needle disposal was introduced in the toilets. It was also recognised that the legitimate users of needles (diabetics) may want to dispose of used equipment.

(We have) never taken the view to use so called (blue) 'lights' in public toilets to deter drug users. (Name deleted) has always taken the view that public toilets are for everybody to use and that the public and our cleaning staff should feel safe and confident to use them. I must admit that our experience is that our drug users respect this approach and leave the facilities as they found them. We have never had complaints from the public that they have been put off using our toilets because they are used by drug users.

I have campaigned for a number of years with colleagues in other agencies that public toilets are not provided as safe injecting rooms. But in the absence of anything else ... I would rather needle users access a clean and well lit public toilet; inject safely, and leave rather than go into the bushes, car park or dimly lit alley with no washing provision or proper disposal for needles. 
From the above testimony, an enabling approach to harm reduction, street-based injecting and the environmental management of injecting environments is evident. This may be noted in decisions to avoid blue light installations; the decrease in discarded injecting paraphernalia in the immediate public area and a desire to provide an appropriate, hygienic and illuminated setting for injecting purposes.

It is also worthwhile to reiterate that it was precisely this project in Cambridge (and its approach to drug-related litter management) that received commendation from within a department of central government (Defra 2005). However, divergence from this support for harm reduction may be noticed in an analysis of online media reports of the same setting several years later. For example, four years later in 2013, the exact same facilities were branded as a 'health hazard' (see opening headlines) and the same toilet facilities appear to have been a site of targeted enforcement by the local constabulary. More specifically, as reported in the Cambridge News:

The (police) officer said: "Daily patrols have been undertaken at varied times throughout the day. Police officers have arrested two males for possession and use of drugs in the toilets." He went on to report that police found two men sleeping rough in the toilets and in possession of stolen goods, adding both were arrested. But addicts using the toilet claim they are getting a mixed message. One addict, who did not wish to be named, told the News: "I don't get why they have facilities in the toilets to dispose of our needles after we inject if they are going to arrest us for that very thing. It's a Catch 22.”

This strategic shift noted in Cambridge over a 4-year period appears consistent with the environmental management of the location visualised in Image 2. More accurately it demonstrates the way in which a collision of enforcement and harm reduction procedures establishes environmental uncertainty that is emphasised by conflicting intervention (underpinned by the 'addict's' comment above). Furthermore, the shift towards enforcement procedures in Cambridge (in 2013) would appear inconsistent to the reportage below describing events in 2011 (provided by the same newspaper regarding the same initiative).

Council bosses hope the huge boost in syringes put into sharps bins means addicts are getting the message about disposing of needles safely.

There has been a 56 per cent rise in syringes put into bins or dumped in the city's council-run toilets, new data obtained by the News has revealed.

In 2008, 3,721 needles were collected from the 20 conveniences but that number increased to 4,088 the following year, 5,025 in 2010 and 5,806 so far this year.

Cambridge MP (Name) met police and held an emergency meeting last year on how to tackle the number of dirty syringes discarded in the streets of Cambridge.

(Name) (title of post), said: "I think addicts are getting the message and we welcome the fact that more needles are being disposed of in the correct way. We have been campaigning hard for this and working closely with our partners. This is good news."

(Cambridge News, 02 December 2011, emphases added) ${ }^{1516}$

\footnotetext{
${ }^{15}$ http://www.cambridge-news.co.uk/News/Almost-6000-drugs-needles-disposed-of-in-Cambridge-publictoilets-02122011.htm\#ixzz2nqOYLrHp
} 


\section{Discussion}

Presented above are two case studies of a public health and community safety initiative (located in two different English towns/cities) that has been here termed the 'Cambridge Model'. Both projects attempted to establish enabling environments for the practice and principles of harm reduction to occur and were housed within bespoke, stand-alone public toilets in 'high street' settings. Furthermore, the design and intent of the initiative in question has been previously applauded by Defra, a body within central government dedicated to environmental concerns (such as drug-related litter in community settings). However, despite the well-intended introduction of the initiative by particular sectors of local authority in the relevant settings, any harm reduction value attached to the scheme appears to have gradually eroded over time. Indeed, it is perhaps more accurate to state that all harm reduction value of the safer toilet scheme (in these settings) appears to have been undermined by enforcement procedures including the targeted policing of injecting drug users.

Accordingly, one may conclude that statutory guidelines pertaining to harm reduction at a national (macro) level are challenged by opposing authorities at a local (micro) level. In this regard, good practice guidelines relating to harm reduction are disregarded in the interests of the environmental management of drug-related litter, street-based injecting and people who inject drugs.

Indeed, this situation does not appear unique to the two the urban settings described above. Findings from Blenkharn's (2008) online audit of drug-related litter management strategies by services throughout the UK describe inconsistent collection procedures conducted by over 500 organisations (including statutory bodies). Blenkharn notes that some organisations promoted 'confused, inadequate and misleading information' with materials disseminated to the general public regarding the appropriate collection and discarding of drug-related litter. Similarly, the audit noted only limited evidence of dedicated drug-related litter bins made available in 'high risk areas' of street-based injecting drug use. Given the direction and assistance available from central government (Defra 2005), these inconsistent approaches to the management of discarded injecting paraphernalia at a unitary level appear to further support the conclusion above. In addition, the apparent lack of dedicated drug-related litter bins installed in public settings for 'safer' disposal of injecting paraphernalia appears equally disconcerting given the positive evaluation such low-threshold intervention has previously received in numerous international settings (Parkin 2013, Defra 2005, Riley et al 1998, de Montigney et al 2010).

\section{Colliding Intervention in Public Spaces: An Empirical Demonstration of 'Risk Environment'}

Despite a history of demonstrable impact upon public health and community safety (op.cit), many harm reduction initiatives are consistently viewed with caution, controversy and/or objection (Colon and Marston, 1999; Drucker, 2006; Forte, 2002; Korner and Treloar, 2003; Smith, 2010; Strike et al., 2004; Takahashi, 1997; Ti and Kerr, 2014; Treloar and Fraser, 2007). This hesitancy is typically shared at micro-levels of society, especially by local authority, provincial media outlets and the general public. This resistance to harm reduction in community settings therefore appears to establish a policy-related paradox; as the practice and principles of such initiatives are typically supported within national policy frameworks as

\footnotetext{
${ }^{16}$ Postscript: Events in Cambridge surrounding drug-related litter continue to make local news. In April 2015, the Cambridge News provided a map of ' 16 top hotspots where dirty needles are found' in various public settings during the first quarter of 2015. See:

http://www.cambridge-news.co.uk/16-hotspots-dirty-needles-Cambridge-map/story-26410740detail/story.html\#ixzz3g8m2h84t Accessed 17 July 2015
} 
part of strategic intervention to protect public health and reduce drug-related harm and hazard.

A demonstration of this paradox has been presented above, in which an environmentallybased initiative (designed to protect public health and reduce discarded injecting equipment in street-based / community settings) within sites of public convenience is regarded from a variety of conflicting perspectives. From a local authority perspective, the initiative may be regarded as an attempt to establish enabling environments for harm reduction to occur in a manner that is consistent with central government guidelines regarding the proactive, environmental, management of drug-related litter. Furthermore, the explicit aim of drugrelated litter bins in toilet cubicles is to provide discrete locations for the anonymous and concealed disposal of used injecting equipment. However, this aim has also been interpreted as the implicit creation of informal injecting cubicles from the perspective of people who inject drugs. Accordingly, when such locations become the focus of a third perspective, (that of increased policing and enforcement procedures by local constabularies), street-involved individuals view the initiative with suspicion and caution. A fourth perspective lies in (mainly pejorative and/or moralistic) reports published online and in local media outlets that typically portray public toilets affected by injecting episodes as environments despoiled and corrupted by dirt, danger and/or disease. Collectively, these various micro-level perspectives concerning enabling environments, harm reduction, law enforcement and stigma collide to establish a socially-constructed 'risk environment' in which it appears uncertain to the central protagonists whether street-based injecting drug use is a public health issue, a communitysafety issue, a criminal issue or a moral issue.

For the above reasons, this paper provides an empirical assessment of the 'risk environment' thesis advocated by Tim Rhodes (2002, 2009) which seeks to provide a sociological framework for understanding (and reducing) drug-related harm. According to Rhodes, this framework defines the risk environment as the physical and social spaces in which a variety of micro/macro level factors interact to increase opportunities for drug-related harm to be reduced and/or produced. Consequently, consideration of the risk environment thesis seeks to 'understand the environmental determinants of harm as a means to creating 'enabling environments' for harm reduction' (Rhodes 2002, 91). However, as noted throughout this paper, the establishment of enabling environments (the 'Cambridge Model') in various community settings does not always have the desired effect of reducing drug-related harm. Instead, the colliding interventions; including the micro-level interpretation of macro-level policies and continued episodes of street-based injecting highlight the difficulties raised by competing social/structural factors that may increase vulnerability to drug-related harm. These factors relate to the informal establishment of street-based injecting environments by people who use drugs; the role of policing and targeted enforcement by local constabularies and the negative portrayal of enabling environments and street-based injecting environments within provincial media reports.

Whereas the appropriation of street-based injecting environments (within toilet cubicles) should be regarded as an outcome of assorted situated necessities by people who use drugs (relating to disadvantage and inequity), the surrounding environmental pressures brought about by increased policing provides opportunities for drug-related harm to continue. This harm may include detention and arrest; rushed preparation/injection; displacement of injecting to more concealed locations and may subsequently diminish the efforts of NSP, outreach workers and municipal authority in minimising such hazards. At the very least, these conflicting practices of applied drug policy and spatial management suggest that a micro- 
level interpretation of each is somehow disconnected from macro-level strategies. Furthermore, local level intervention does not necessarily reflect a strategic, joined-up approach and/or politically integrated response to street-based injecting drug use.

\section{A European Approach to Local Intervention?}

As noted elsewhere (Chheng et al 2012) successful components of harm reduction initiatives prioritise the coordination and cooperation of various stakeholder organisations and their relevant policies and practice. This principle is advocated consistently throughout Tackling Drug-related Litter (Defra 2005), especially with regard to the formation of local partnerships and joint-working initiatives (between local authorities, community organisations, police constabularies, drug/alcohol services and frontline personnel) seek to provide meaningful responses to issues surrounding street-based injecting. However, as emphasised throughout this paper, such approaches to street-based injecting / drug-related litter do not appear standard responses throughout areas of local authority in England. Indeed, the evidence of colliding intervention noted above suggests there is a need for local authorities and national governments (throughout the UK) to adopt a more inspired, innovative and pragmatic approach to the spatial management of street-based injecting drug use.

One possible approach to reducing drug-related harm in street-based settings may be the introduction of Safer Injecting Facilities ${ }^{17}$ (SIF), especially in locations where concentrated episodes of street-based injecting may frequently occur. Facilities of this nature have been widely available throughout Europe since 1986 (Hedrich 2004, Stoever 2002) and, according to the Drug Policy Alliance (DPA), 92 SIF operated in 62 international cities in 2012 (DPA 2012). SIF are defined as legally-sanctioned, medically-supervised health-care facilities designed primarily to reduce harm associated with drug use (Wright and Tompkins 2004, Kimber et al. 2005). The principal aim of SIF is to provide hygienic environments for individuals to use drugs in a safe and supervised manner and to physically remove them (if only temporarily) from harms associated with injecting in public locations (Hall and Kimber 2005, Wright and Tompkins 2004). In addition, SIF provide low-threshold opportunities that reduce the sharing and discarding of injecting equipment in an environment that prioritises hygiene and risk management. In 2015, no similar amenity exists (or has ever existed) in any location throughout the UK - as they are generally considered too politically controversial to implement (Strathdee and Pollini 2007). Nevertheless, support for such initiatives has been made public by various figures of local authority. For example, both the Chief Constable of Durham Constabulary and the Police and Crime Commissioner for the same region have each advocated $^{18}$ the harm reduction and crime reduction benefits associated with such intervention, as well as highlighting the impact such facilities may have upon the local authority management of drug-related litter. Despite support from such influential individuals, SIF are unlikely to feature in national drug strategies of current/future government. This pessimism may be explained with the emphasis placed upon the singleissue currently at the heart of the national Drug Strategy (HM Government 2010): namely, recovery from dependent drug use (that overtly emphasises a structural shift away from harm reduction policies).

Although SIF may not currently be a viable option in the UK, the spatial management of drug-related issues may be informed by equally pragmatic and innovative models of policy

\footnotetext{
17 also known as Drug Consumption Rooms

${ }^{18}$ http://www.bbc.co.uk/news/uk-england-29566218 and http://www.bbc.co.uk/news/uk-england-24730381

(Accessed 17 July 2015)
} 
design also noted throughout continental Europe. For example, a European Monitoring Centre for Drugs and Drug Addiction (EMCDDA 2015) report regarding 'drugs policy and the city' acknowledges that 'the adoption of drugs strategies at national level has become a standard feature of the public administrative response to drug problems in Europe, (but) a more unclear and complex situation exists at city level' (2015, 3, emphasis added). In short, different cities have different drug issues to address in which a generic national strategy is not always appropriate. For this reason a number of European cities have developed 'city-level policies' that provide bespoke responses to issues (such as open drug scenes, proactive outreach, drug tourism) considered environmentally and spatially specific to those settings. Perhaps most significantly, city level policies 'can mirror or depart from the concerns of national ones' (ibid, 13) in which city authorities formulate a strategic response that runs parallel the interests of the state.

Accordingly, the introduction of a 'city-level policy' by unitary and municipal authorities throughout the UK may provide a framework for more networked and complementary responses to locally relevant concerns. Such an approach would unite key stakeholders in providing a co-ordinated and synchronised response to local issues (such as street-based injecting and drug-related litter management) with the aim of avoiding the various collisions identified above. Indeed, the necessary structures to implement a city-level policy appear to already exist in the form of local authority resources, drug and alcohol services and locally elected Police and Crime Commissioners. In an idealistic setting, these various actors would formulate local policy dedicated to solution-focused, harm reduction responses to geographically relevant issues within their particular administrative area. Indeed, a microlevel partnership of this design would also appear consistent with attempts to reduce drugrelated harm within a local framework that prioritises the underlying constructions of indigenous 'risk environments'. Furthermore, a micro-level policy of this design may actually complement any macro-level national drug strategy (and may even facilitate the aims and objectives of single-themes within the latter).

Finally, in the absence of such innovative approaches to drug policy, it is perhaps worth noting that 'public health and harm reduction are parallel social movements' (Rhodes 2002, 85) that share common ground with regard to the reduction of health-related risk and harm via individual, community, policy and environmental change. However, such goals may not be achieved if attempts at creating environments for enabling harm reduction are disrupted by intervention that is characterised by collision. 


\section{Acknowledgements}

The views, opinions and academic content within in this paper are those of the author. These views, opinions and interpretations should not necessarily be associated with any previous/current body/people associated with the research described throughout this text. In addition, these views and opinions are not necessarily shared or held by any institution to which the author has been previously or currently attached (especially those associated with the author's current position at the University of Manchester).

The author acknowledges the support of Mr. G. Halksworth for this paper. The author thanks the relevant authority for its permission to reproduce visual data obtained from the relevant study described in this work (which must remain anonymous to be consistent with the text).

Selected paragraphs in this paper have been reproduced with permission (in an amended and edited form) from Parkin, S. (2014) An Applied Visual Sociology: Picturing Harm Reduction. Farnham: Ashgate/Gower, Copyright (C) 2014. 


\section{References}

ACMD, 1988. AIDS and Drug Misuse. Part 1 (Report by Advisory Council on the Misuse of Drugs). HMSO, London.

Berridge, V., 2012. The rise, fall, and revival of recovery in drug policy. Lancet, 379, 9810, $22-23$.

Blenkharn, J.I., 2008. Clinical wastes in the community: local authority management of discarded drug litter. Public Health 122, 725-728.

Cabinet Office, 1998. Tackling Drugs to Build a Better Britain. Cabinet Office, HMSO, London.

Cameron, D., 2012. Conservative Party Conference Keynote Speech, Conservative Party Annual Conference, Birmingham, 10 October 2012

http://www.theguardian.com/news/datablog/2012/oct/10/david-cameron-conservative-partyconference-speech Accessed 05 April 2014

Chheng, K., Leang, S., Thomson, N., Moore, T., Crofts, N., 2012. Harm reduction in Cambodia: a disconnect between policy and practice. Harm Reduction Journal, 9: 30

Colon, I., Marston, B., 1999. Resistance to a Residential AIDS Home. Journal of Homosexuality 37, 135-145.

Crabtree, A., Mercer, G., Horan, R., Grant, S., Tan, T. and Buxton, J.A., 2013. A qualitative study of the perceived effects of blue lights in washrooms on people who use injection drugs. Harm Reduction Journal, 10, 22

DPA, 2012. Supervised Injection Facilities: Resource Sheet. Drug Policy Alliance DPA, New York.

de Montigney, L., Moudon, A.V., Leigh, B., Young, K., 2010. Assessing a drop box programme: A spatial analysis of discarded needles. International Journal of Drug Policy 21, 208-214.

DeBeck, K., Small, W., Wood, E., Li, K., Montaner, J.S.G., Kerr, T., 2009. Public injecting among a cohort of injecting drug users in Vancouver, Canada. Journal of Epidemiology and Community Health 63, 81-86.

Defra, 2005. Tackling Drug-related Litter: Guidance and Good Practice. Department for Environment, Food and Rural Affairs, London.

Department of Health (DoH), 1995. Tackling Drugs Together. Department of Health, London.

Dovey, K., Fitzgerald, J., Choi, Y., 2001. Safety becomes danger: dilemmas of drug-use in public space. Health and Place 7, 319-331. 
Drucker, E., 2006. Insite: Canada's landmark safe injecting program at risk. Harm Reduction Journal 3.

Duff, C., 2009. The drifting city: the role of affect and repair in the development of 'enabling environments'. International Journal of Drug Policy 20, 202-208

EMCDDA, 2015. Drugs policy and the city in Europe. European Monitoring Centre for Drugs and Drug Addiction, Lisbon, Portugal.

Fitzgerald, J., Dovey, K., Dietze, P., Rumbold, G., 2004. Health outcomes and quasisupervised settings for street injecting drug use. International Journal on Drug Policy 15, 247 - 257.

Fitzgerald, J.L., 2005. Policing as public health menace in the policy struggles over public injecting. International Journal of Drug Policy 16, 203-206.

Forte, J.A., 2002. Not in my social world: a cultural analysis of media representations, contested spaces and sympathy for the homeless. Journal of Sociology and Social Welfare 29.

Fry, C.L., 2002. Injecting drug user attitudes towards rules for supervised injecting rooms: implications for uptake. International Journal of Drug Policy 13, 471-476.

Galvani, S., 2012. Supporting People with Alcohol and Drug Problems. Policy Press, Bristol.

Green, T., Hankins, C., Palmer, D., Boivin, J.-F., Platt, R., 2003. Ascertaining the need for a Safer Injecting Facility (SIF): the burden of public injecting in Montreal, Canada. Journal of Drug Issues, 713-732.

HM Government, 2010. Drug Strategy 2010: Reducing Demand, Restricting Supply, Building Recovery: Supporting People to Live a Drug Free Life. HMSO, London.

HM Government, 2008. Drugs: protecting families and communities: The 2008 drug strategy. Home Office, London.

HPA, 2012. Shooting Up: Infections among people who inject drugs in the United Kingdom 2011. Health Protection Agency, Health Protection Scotland, Public Health Wales, and Public Health Agency Northern Ireland, London.

Hall, W. and Kimber, J., 2005. Being realistic about benefits of supervised injecting facilities. The Lancet 18 March 2005.

Hedrich, D., 2004. European Report on Drug Consumption Rooms. European Monitoring Centre for Drugs and Drug Addiction, Luxemburg.

Heed, K., 2006. Response: If enforcement is not working, what are the alternatives? International Journal of Drug Policy 17, 2, 104-106

Hunt, N., Lloyd, C., Kimber, J., Tompkins, C., 2007. Public injecting and willingness to use a drug consumption room among needle exchange programme attendees in the UK. International Journal of Drug Policy 18, 62-65. 
Kimber, J., Dolan, K. and Wodak, A., 2005. Survey of drug consumption rooms:service delivery and perceived public health and amenity impact. Drug and Alcohol Review 24, 21-4.

Korner, H., and Treloar, C., 2003. Needle and syringe programmes in the local media: 'needle anger' versus 'effective education in the community'. International Journal of Drug Policy 15, 46-55.

MacPherson, D., Mulla, Z., \& Richardson, L., 2006. The evolution of drug policy in Vancouver, Canada: Strategies for preventing harm from psychoactive substance use. International Journal of Drug Policy, 17, 2, 85-95.

Marshall, B.D., Kerr, T., Qi, J., Montaner, J.S.G., Wood, E., 2010. Public injecting and HIV risk behaviour among street-involved youth. Drug and Alcohol Dependence 110, 254-258.

McKnight, I., Maas, B., Wood, E., Tyndall, M.W., Small, W., Lai, C., Montaner, J.S.G., Kerr, T., 2007. Factors associated with public injecting among users of Vancouver's Supervised Injecting Facility. American Journal of Drug and Alcohol Abuse 33, 319-326.

Monaghan, M., 2012. The recent evolution of UK drug strategies: from maintenance to behaviour change. People, Place and Policy Online 6, 29-40.

Moore, D. and Dietze, P., 2005. Enabling environments and the reduction of drug-related harm: reframing Australian policy and practice. Drug and Alcohol Review, 24, 275-284

Navarro, C., Leonard, L., 2004. Prevalence and factors related to public injecting in Ottawa, Canada: implications for the development of a trial safer injecting facility. International Journal of Drug Policy 15, 275 - 284.

NICE, 2014. Needle and syringe programmes: NICE public health guidance 52.

PHE, 2013a. Hepatitis C in the UK. Public Health England, London.

PHE, 2013b. Shooting Up: Infections among people who inject drugs in the UK (2012). Public Health England, London.

Parkin, S., 2014. An Applied Visual Sociology: Picturing Harm Reduction. Farnham, Ashgate Publications Ltd.

Parkin, S., 2013. Habitus and Drug Using Environments: Health, Place and Lived Experience. Farnham, Ashgate Publications Ltd.

Parkin, S., 2011a. Colliding Interventions: the problematising of public injecting drug use. Contemporary Drug Problems Conference: Beyond the Buzzword: Problematising 'Drugs'; Prato, Italy, 3-5 October, 2011

Parkin, S., 2011b. Identifying and Predicting Drug-Related Harm with Applied Qualitative Research. In Katz, J, Peace, S. and Spurr, S. (eds) Adult Lives: A Life Course Perspective. Policy Press, Bristol. 
Parkin, S. 2009. The effect of place on health risk: a qualitative study of micro-injecting environments. Unpublished $\mathrm{PhD}$ Thesis. University of Plymouth.

Parkin, S., 2008. From One Space to Another. The Displacement of Risk Behaviour (Injecting Drug Use) in an Urban Environment. Ways of Living: Inequalities, Risks and Choices. 1st Annual ENQUIRE Conference, University of Nottingham, 17-18 June 2008.

Parkin, S. and Coomber, R. 2011a. Public Injecting Drug Use and the Social Production of Harmful Practice in High-Rise Tower Blocks (London, UK): A Lefebvrian Analysis. Health and Place, 17, 717-726.

Parkin, S., \& Coomber, R., 2011b. Injecting Drug User Views (and Experiences) of Drugrelated Litter Bins in Public Places: A Comparative Study of Qualitative Research Findings Obtained from UK Settings. Health \& Place, 17, 1218-1227.

Parkin, S., \& Coomber, R., 2010. Fluorescent Blue Lights, Injecting Drug Use and Related Health Risk in Public Conveniences: Findings from a Qualitative Study of Micro-Injecting Environments. Health and Place, 16, 629-637.

Parkin, S., \& Coomber, R., 2009a. 'Informal Sorter Houses': A Qualitative Insight of the 'Shooting Gallery' Phenomenon in a UK Setting. Health and Place, 15, 981-89

Parkin, S., \& Coomber, R. 2009b. Public Injecting and Symbolic Violence. Addiction Research and Theory, 17, 4, 390-405.

Parkin S., \& Coomber, R., 2009c. An Informal Evaluation of Drug-Related Litter Bins in Plymouth City Centre. University of Plymouth. (Unpublished Report for Plymouth Drug and Alcohol Action Team)

Parkin S., \& Coomber, R., 2008. A Comparative Study of Drug Related Litter Collected in Plymouth During 2006-2007 and 2007-2008. University of Plymouth. (Unpublished Report for Plymouth Drug and Alcohol Team)

Parkin S., \& Coomber, R., 2007. A Rapid Appraisal of Public Injecting Sites and Drug Related Litter in Plymouth. University of Plymouth. (Unpublished Report for Plymouth Drug and Alcohol Action Team)

Pearson, M., Parkin, S., Coomber, R., 2011. Generalizing applied qualitative research on harm reduction: the example of a public injecting typology. Contemporary Drug Problems 38, 61-91.

Philipp, R., 1993. Community needlestick accident data and trends in environmental quality. Public Health 107, 363-369.

Rhodes, T. 2002. The 'risk environment': a framework for understanding and reducing drugrelated harm. International Journal of Drug Policy 13, 85-94

Rhodes, T. 2009. Risk environments and drug harms: A social science for harm reduction approach. International Journal of Drug Policy 20, 193-201 
Rhodes, T., Kimber, J., Small, W., Fitzgerald, J., Kerr, T., Hickman, M., Holloway, G., 2006. Public injecting and the need for 'safer environment interventions' in the reduction of drugrelated harm. Addiction 101, 1384-1393.

Rhodes, T., Watts, L., Davies, S., Martin, A., Smith, J., Clark, D., Craine, N., Lyons, M., 2007. Risk, shame and the public injector: a qualitative study of drug injecting in South Wales. Social Science and Medicine 65, 572-585.

Riley, E., Beilenson, P., Vlahov, D., Smith, L., Koenig, M., Jones, T.S., Doherty, M., 1998. Operation Red Box: a pilot project of needle and syringe drop boxes for injection drug users in East Baltimore. Journal of Acquired Immune Deficiency Syndrome Human Retrovirology 18, S120-125.

Robertson, R., 1990. The Edinburgh Epidemic: A Case Study., in: Strang, J., Stimson, G.V. (Eds.), AIDS and Drug Misuse: The Challenge for Policy and Practice in the 1990s. Routledge, London, pp. 95-107.

Room, R., 2006. Response. Drug policy and the city. International Journal of Drug Policy $17,2,136$

Scottish Government, 2008. The Road to Recovery: A New Approach to Tackling Scotland's Drug Problem. The Scottish Government, Edinburgh.

Small, W., Rhodes, T., Wood, E., Kerr, T., 2007. Public injection settings in Vancouver: physical environment, social context and risk. International Journal of Drug Policy 18, 2736.

Smith, C.B.R., 2010. Socio-spatial stigmatization and the contested space of addiction treatment: Remapping strategies of opposition to the disorder of drugs. Social Science and Medicine 70, 859-866.

Stimson, G.V., 2000. Blair declares war: The unhealthy state of British drug policy. International Journal of Drug Policy 11, 259-264.

Stimson, G.V., Alldritt, L., Dolan, K., Donoghoe, M., 1988. Syringe exchange schemes for drug users in England and Scotland. British Medical Journal 296 1717-1719.

Stoever, H., 2002. Crack cocaine in Germany: Current state of affairs. Journal of Drug Issues 32, 413-421.

Strang, J., Gossop, M., 2005. The 'British System' of drug policy: extraordinary individual freedom, but to what end?, in: Strang, J., Gossop, M. (Eds.), Heroin Addiction and the British System: Volume 2: Treatment and Policy Responses. Routledge, Abingdon, pp. 206-219.

Strathdee, S.A. and Pollini, R.A., 2007. A 21st-century Lazarus: The role of safer injection sites in harm reduction and recovery. Addiction 102, 848-9.

Strike, C.J., Myers, T., Millson, M., 2004. Finding a place for needle exchange programs. Critical Public Health 14, 261-275. 
Takahashi, L.M., 1997. The socio-spatial stigmatization of homelessness and HIV/AIDS: toward an explanation of the NIMBY syndrome. Social Science and Medicine 45, 903-914.

Taylor, A., Cusick, L., Kimber, J., Rutherford, J., Hickman, M., Rhodes, T., 2006. The social impact of public injecting (Independent Working Group on Drug Consumption Rooms). Joseph Rowntree Foundation, p. Paper D.

Ti, L., Kerr, T., 2014. The impact of harm reduction on HIV and illicit drug use. Harm Reduction Journal 11:7 http://www.harmreductionjournal.

Treloar, C., Fraser, S., 2007. Public opinion on needle and syringe programmes: avoiding assumptions for policy and practice. Drug and Alcohol Review 26, 355-361.

Wright, N.M.J. and Tompkins, C.N.E., 2004. Supervised injecting centres. British Medical Journal 328, 100-2. 